\title{
Design Out Waste Framework for Achieving Sustainability in Public Housing Projects in Egypt
}

\author{
AYMAN A. E. OTHMAN, LAILA A. ELSAWAF \\ Architectural Engineering Department \\ The British University in Egypt \\ Cairo-Suez Desert Road, \\ El-Shorouk 11837, Cairo, EGYPT
}

\begin{abstract}
Due to the increasing population worldwide, Public housing projects (PHPs) have witnessed a rapid increase during the previous decades. Simultaneously, this generated a substantial amount of waste that represents roughly $40 \%$ of the solid waste produced by the construction industry every year. Being one of the significant phases of the construction process, the choices made during the design process play a crucial role towards increasing the solid waste created during the construction phase, which eventually affected the sustainability of the developed projects. This called for considering innovative strategies that reduce construction waste during the design process. This paper aims to develop a framework to facilitate the implementation of Design out waste (DOW) strategy to achieve sustainability in PHPs in Egypt. A research methodology based on literature review, case studies and survey questionnaire was developed to achieve the above mentioned aim. The developed framework represent a synthesis that is novel and creative in thought as it is the first study to discuss the implementation of DOW strategy towards achieving sustainability in PHPs in Egypt.
\end{abstract}

Keywords: Design Out Waste Strategy, Sustainability, The design Process, Public Housing Projects, Waste Management, Egypt.

Received: September 25, 2020. Revised: March 12, 2021. Accepted: March 24, 2021. Published: April 1, 2021.

\section{Introduction}

The construction industry is an important sector that contributes significantly towards accomplishing the sustainable economic and social targets at national and international levels. It is one of the leading global economic industries that generates an annual output of US 3000 billion Dollars which represents about $10 \%$ of the world's gross domestic product (GDP) [1]. In Egypt, the construction industry plays a role concerning the growth of the economy through offering job opportunities, increasing GDP, arranging for the majority of the country's fixed capital assets and supporting other industrial segments to prosper. It is accountable for employing $11 \%$ of the total population and growing GDP by $5 \%$ and has a roughly 32 public and 36000 private contracting firms [2]. In addition, it provides infrastructure projects and utility facilities that satisfy the needs and meet the expectations of the community. The current population of Egypt is 103,493,606 as of 8th February, 2021, which is equivalent to $1.31 \%$ of the total world population [3]. The annual growth rate of population in Egypt called for the establishment of the National Social Housing project that aims to offer 100,000 units to provide citizens with quality of life dwellings. Despite the aforementioned positive impacts on the Egyptian economy and society, the development of these projects was associated with significant adverse environmental impact relating to the construction waste generated at different stages. It is noted that at least $10 \%$ of materials cost is wasted in construction projects of developing countries [4]. The architectural design process is one of the crucial processes in construction. This is because the decisions made during this process affect the project performance throughout its life cycle [5\&6]. Osmani [7] stated that the waste generated during the construction stage is a result of improper decisions made during the design process or due to the lack of guidelines and regulations that avoid waste generation [8]. Accordingly, this paper aims to develop a framework to facilitate the implementation of DOW strategy to achieve sustainability objectives in PHPs in Egypt.

\section{Research Objectives and Methods}

In order to achieve this aim, a research methodology consists of literature review, case studies and survey questionnaire was developed to: 
- investigate the nature of the construction industry in Egypt, waste in PHPs, designout-waste strategy and sustainability.

- Compare between two case studies to examine the benefits delivered due to the implementation of DOW strategy or missed due to the lack of minimizing waste causes during the design process.

- Examine the awareness and application of Architectural Design firms (ADFs) towards DOW strategy as an approach to minimize construction waste during the design process. This objective was accomplished through a survey questionnaire conducted with a sample of ADFs in Egypt.

- develop a framework to facilitate the implementation of DOW strategy to assist ADFs achieving sustainability in PHPs.

\section{Literature Review}

\subsection{Nature of the Egyptian Construction Industry}

Egypt is one of the leading manufacturers of reinforced steel and cement in the Middle East by 1.7 billion loans of steel and 56 million tons of cement respectively. As part of the National Strategic Development Strategy, the Egyptian government is intending to develop 44 urban communities across the nation by 2052 with a yearly financial plan of US\$ 850 million. Moreover, the Government has planned to develop an Airport City, environmental friendly power projects, 3 new power stations, 10 new solar stations, national housing projects and the Suez Canal corridor project in several governorates with investment of US\$ 70 billion. Despite the boom of construction in Egypt, the industry is censured for its negative effect on the climate. In 2012, 89.03 million tons of solid waste was produced in Egypt in which 4 million tons were construction and demolition waste. This problem is mainly linked to the conventional procurement approaches embraced in the Egyptian construction industry and the powerlessness to deal with the various difficulties regarding waste generation and contamination of the climate. This required the construction industry to be innovative, smart and consider sustainable solutions that tackle waste generation at early phases of the project life cycle. Moreover, the use of Public Private Partnerships is encouraged to finance public sector projects and share experience of project participants [9].

\subsection{Waste in Public Housing Projects}

Like many other countries worldwide, the construction industry is one of the major solid waste generators in Egypt [10]. The extensive building and infrastructure projects have resulted in a huge expansion of construction waste generation. The latest report of the Egyptian Ministry of Environment highlighted that Egypt generates about 90 million tonnes of total solid waste annually, in which 5.8 million tonnes are construction and demolition waste. Construction wastes has become a a difficult issue and variously affects the economy, environment and society. In Egypt, the solid waste management system is feeble and incompetent where $81 \%$ of created solid waste are unloaded on roads of residential areas and at illegal unloading sites with no treatment [11]. There are a number of causes that lead to waste generation in construction projects, especially PHPs. This incorporate absence of considering effective solutions during the design process, lack of authoritarian measures and procedures in the solid waste management sector, restricted public awareness about the environmental issues, inadequate allocated assets, lack of coordination among partners, deficiency of prepared and qualified personnel, and lack in specialized and operational dynamic [12 \&13].

\subsection{Sustainability}

Sustainability is described as the ability to fulfil the needs of the current generation without preventing the future generation from achieving their needs as well [14]. It aims to develop and maintain a balance between the three bottom line of sustainability (i.e. society, economy and environment) conditions that enable human being to live in a productive harmony with nature now and in the future [15]. Sustainability focuses on protecting the environment, improving society and enhancing economy [16]. Maxwell [17] stated that integrating sustainability concepts during the early stages of any project will ensure the successful delivery of sustainable projects. Sustainability has three dimensions as follows:

- The environmental dimension aspect concentrates on employing natural resources in an efficient way; minimising waste, pollution, effluent generation and emissions to the environment. Moreover, it focuses on reducing the negative impact on human health, encouraging the use of renewable raw materials and eliminating toxic materials [18].

- The social dimension focuses on delivering projects that fulfil community needs, distributing resources equally and not 
discriminating people according to their mental or physical ability, age, culture, gender, race, religion, sexual orientation and socio-economic status [19]. These rights, that contribute towards a quality of life, include the rights to worship, housing, social security, work, travel, own property and freedom of speech.

- The economic dimension focuses on offering job opportunities, enhancing the quality of the education system and health care programmes [20]. Economic sustainable community is one that is capable to use the available resources in an efficient way to provide community members with their needs without seeking help from neighbouring communities or nations [21].

\subsection{The Architecture Design Process}

The architecture design process is one of the critical process in the construction industry. It plays a crucial role towards translating the client requirements into engineering drawings and technical specifications. In addition, choices made during this process affect the project performance during its life cycle. These choices incorporate but not limited to end-users' involvement, waste elimination, cost reduction, materials and systems selection and sustainable design elements [22].

\subsubsection{Stages of the Design Process}

The Royal Institute of British Architects (RIBA) plan of work update expressed that the life cycle of a project consists of seven phases, specifically, strategic definition, preparation and briefing, concept design, spatial coordination, technical design, manufacturing and construction, handover and use. Each stage has its own definition, scope of work and participants. This paper will focus on the preconstruction stages:

\section{(a) Preparation and Briefing}

The core tasks carried out during this stage involve preparing the project brief including project expected results and sustainability results; quality goals and spatial needs, undertaking viability studies; agreeing project budget; source site data including site analysis; getting ready project programme and planning project execution plan [22].

\section{(b) Concept design}

This stage focuses on preparing the architecture concept incorporating strategic engineering requirements and adjusted to cost plan; project procedures and framework determination; concurring project brief criticisms; undertaking design reviews with client and project stakeholders and preparing stage design programme [22].

\section{(c) Spatial Coordination}

The core tasks of the spatial coordination stage are concerned with conducting design studies, engineering investigation and cost activities to test architecture concept leading to spatially; planning configuration adjusted to refreshed expenses plan, project procedures and layout detail; developing change control techniques and preparing stage design programme [22].

\section{(d) Technical design (TD)}

The technical design stage is concerned with developing architecture and technical design, conducting and coordinating design team building systems information, preparing and integrating specialised subcontractor, building systems information and organising stage design programme [22].

\subsection{Design Out Waste Strategy}

DOW strategy is described as building principles that use resources in an efficient way during the design process of construction projects so as to reduce the quantity of waste created during the construction process. DOW could be incorporated into the design process to assess the waste generated and recognize how to be reduced to enhance project's constructability, reduce cost and time and enhance quality. The UK waste and resources action programme which developed this strategy to minimise waste during design process has provide five main fundamental approaches:

- Design for Waste Efficient Procurement

- Design for Materials Optimization

- Design for Off-Site Construction

- Design for Reuse and Recycling

- Design for Deconstruction and Flexibility.

\subsubsection{Principles Of Design Out Waste}

- Design for waste efficient procurement This approach encourages the engagement of designer within both the design and construction processes. This helps in considerations that direct workflows. In addition, it uses documents that facilitate setting the waste performance requirements, support supply chain coordination, recognize the source accountable for reused substances and materials. Moreover, it reduces the required packaging used for materials 
procurement and prepare plans for site waste management plan (SWMP) and consider logistics material delivery on time.

\section{- Design for material optimization}

This approach focuses on the efficient use of materials during the design process. In addition, it facilitates the building design layout, form, elements and following design standards, technical aspects and dimensions. Moreover, it encourages the use of local materials and specifies recycled contents as well as considers the building maintainability, services and replacement of defected components throughout the building life cycle.

\section{- Design for offsite construction}

This approach states that through the early phases of the construction project, designers with the collaboration with contractors have to agree on the use of prefabricated building elements in order to enhance the performance of the project supply chain. In addition, this principle promotes the use of modular volumetric construction, offsite prefabricated structure elements, pods, bathrooms and pre-cut building components.

\section{- Design for reuse and recycling}

This approach is concerned with the reuse of recycled materials throughout the whole life cycle. In addition, it encourages the reuse of materials and components resulted from building demolition.

\section{- Design for deconstruction and flexibility}

This approach is considered an important principles of DOW strategy. It encourages designers to consider the maintenance and refurbishment issues during the design process through studying the effective recovery of materials during the life cycle of the building [23].

As a result of literature review, the research developed a matrix that correlates sustainability, DOW principles and phases of the design process to be used to analyse the case studies.

Some relevant studies can be found in [28] and [29].

\section{Case Studies}

A comparison between two case studies from UK and Egypt was conducted to investigate the benefits achieved as a result of implementing DOW strategy or missed due to the lack of minimizing waste causes during the design process.

\subsection{Case Study (1): Tigh-Na-Cladach Housing Project, Dunoon, UK.}

This case study presents the construction of 15 lowenergy houses which represent the first social passive house in UK. The early collaboration between the designer and the contractor resulted in developing the project scheme of the passive house using the DOW strategy. The quantity surveyor proposed to reduce the project cost by $15 \%$ through waste savings. The Scottish passive house centre supported the project through calculations, supplying components and advising on testing for the certifications. The DOW principles were integrated in the design process. This included the design of 10 gables compacted terrace to reduce heat gain through utilising the prevailing wind and providing insulation and improved cost reduction, see figures $(1 \& 2)$

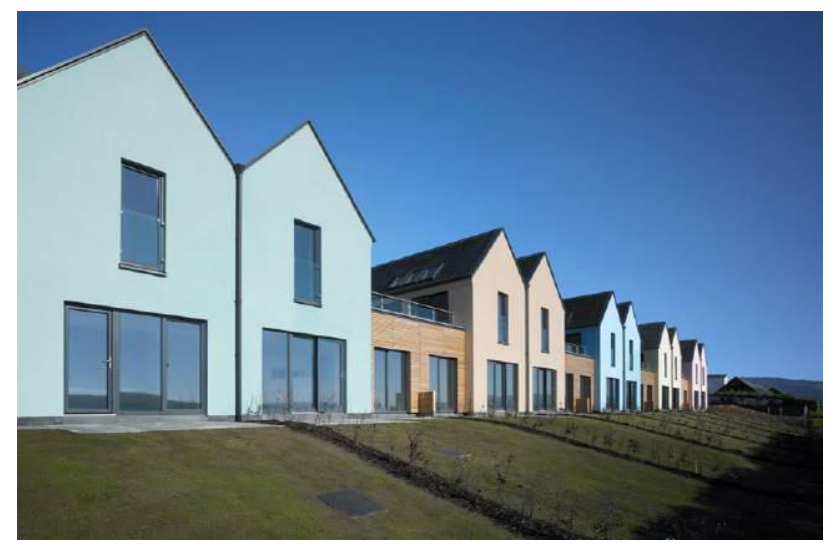

Figure (1) Tigh-Na-Cladach Housing Project [23]

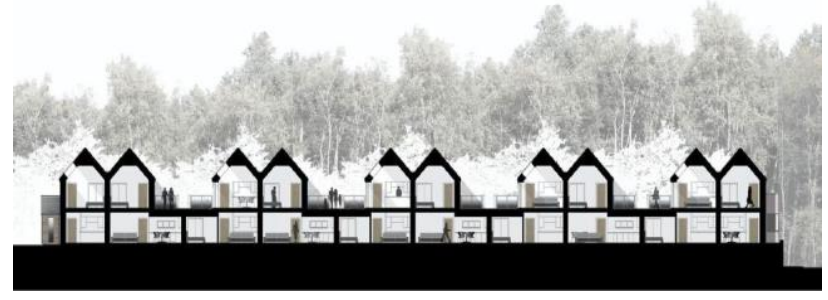

Figure (2) Section of the Tigh-Na-Cladach Housing Project [23]

Moreover, an extra 50mm of insulation was applied on the roof and around the frames of glazing. The project was equipped with Mechanical, Ventilation and Heat Recovery components which collect hot air from kitchens and bathrooms and utilise it for raising 
the temperature of the fresh air and distributes to the bedrooms and lounge, see figure (3).

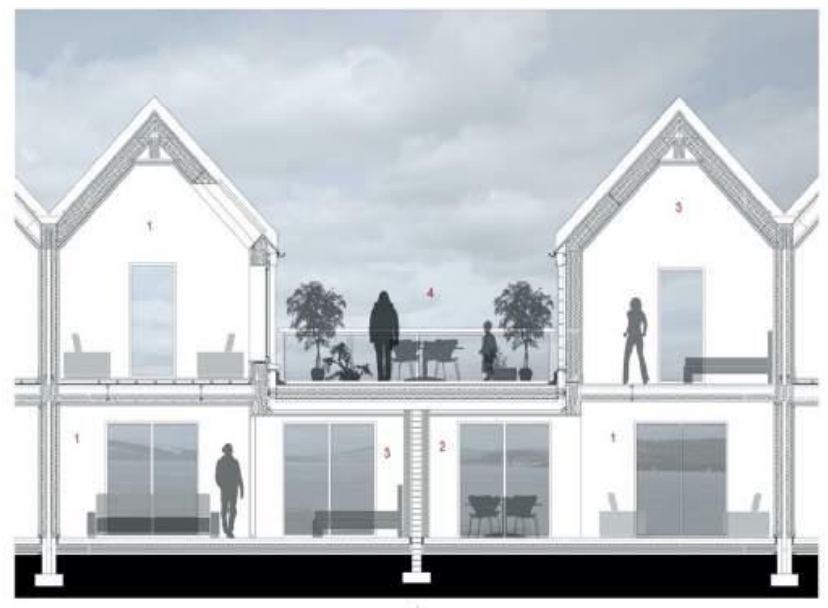

Figure (3) Insulation of Tigh-Na-Cladach Housing Project [23]

The project saved approximately $£ 300,000$ on the overall budget via eliminating some unnecessary features and elements without affecting the achievement of sustainability objectives or passive house characteristics. All buildings of the project were constructed using the sustainability guidelines and following the code level 4 of environmental homes lifetime standards. All houses in the project were constructed using a pre-assembled closed panels made of timer frame and pre-insulated with $300 \mathrm{~mm} 80 \%$ recycled glass wool insulation in walls and $400 \mathrm{~mm}$ in the roof. All doors and windows were triple glazed [24], see figure (4).

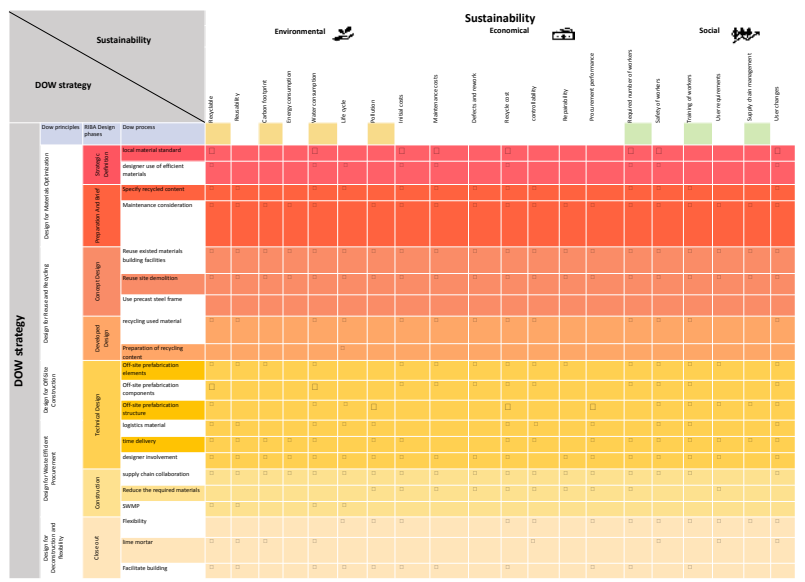

Figure (4) Case Study (1) Analysis of DOW VS. Sustainability Aspects (Developed by The Authors)

The combination between DOW strategy and sustainability aspects has been analysed throughout this matrix providing high efficiency of the case study and how the building achieves sustainability.
As well as, it's the first social Passive House in UK provided as part of an affordable housing initiative.

\subsection{Case Study (2): Egyptian Public Housing Project, El Obour City, Egypt}

The case study presents a residential public housing project constructed by the Egyptian government in 2005 in El Obour City for youth house-holding consisted of 70 buildings. Each building comprised of ground floor, 3 typical floors and roof. The design of the project followed the traditional design process without considering the principles of DOW. During the last 15 years, the project was renovated twice as a result of using non-durable materials and other nonsustainable solutions. Some of the issues that affected the project sustainability is the buildings' orientation which was headed to the undesired wind direction that allowed sunlight to penetrate the building specially in summer causing in non-comfortable indoor climate. Other issues that affected project sustainability is that the project was designed with no energy efficient consideration, especially when Air Conditioning unites used to create comfortable indoor climate in summer which resulted in high electricity bill and waste of energy. Finally, the nonconsideration of the building maintainability during the design process resulted in high maintenance cost, see figures $(5,6 \& 7)$.

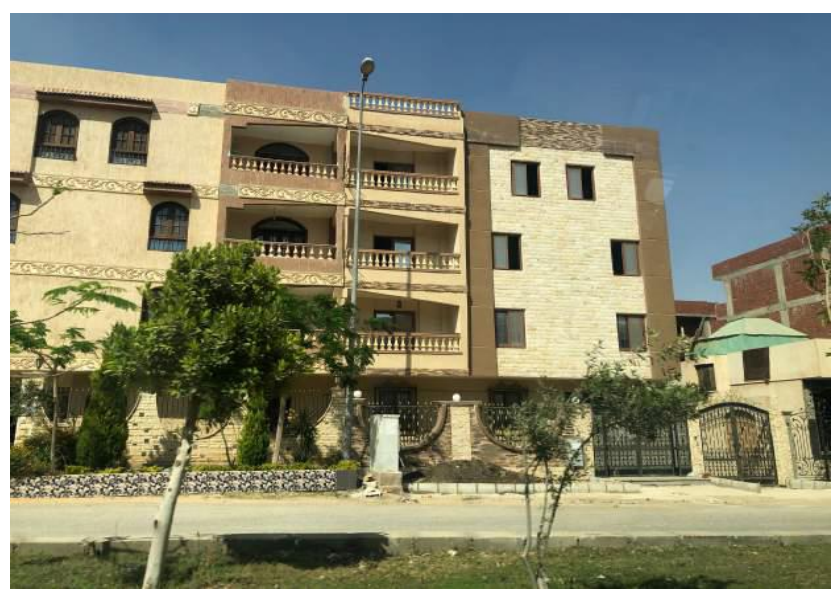

Figure (5) Al Obour City Youth Buildings [25]

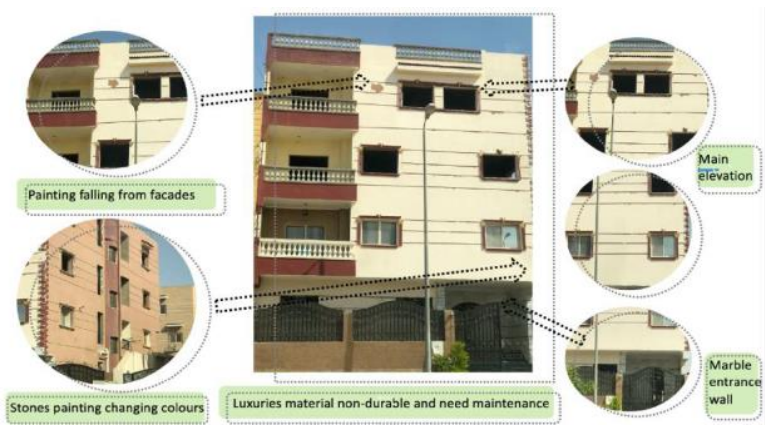

Figure (6) Problems of Al Obour City Youth Buildings [25] 


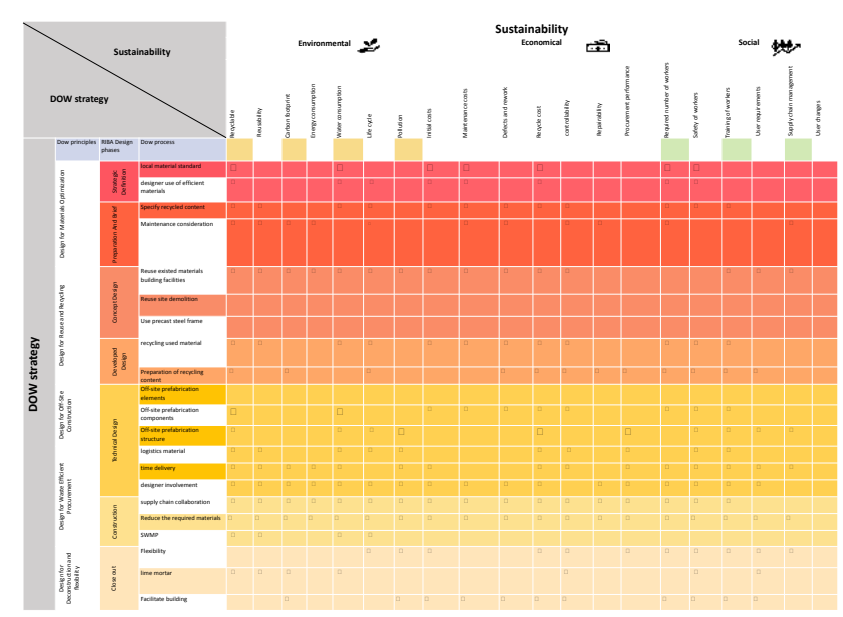

Figure (7) Case Study (2) Analysis of DOW VS. Sustainability Aspects (Developed by The Authors)

\section{Data Analysis}

This segment presents the outcome of a survey questionnaire carried out with a representative sample of ADFs in Egypt to examine their insight and utilization of DOW strategy towards minimizing construction waste during the design process of PHPs. Out of 44 ADFs invited to participate in the study, only 38 firms responded to the survey representing $86.3 \%$ which is sufficient to validate the research findings. Results of the survey questionnaire showed that:

- $68.4 \%$ respondents stated that they are not familiar or have previous experience with the DOW strategy and its principles and accordingly they do not implement this strategy during the design process.

- $54 \%$ of respondents defined the role of implementing DOW strategy at the planning and defining scope followed by controlling the risk and minimize uncertainty.

- $50 \%$ of ADFs that implemented DOW stated that "Design for deconstruction and flexibility" was ranked the most important principle followed equally by "Design for offsite construction", "Design for waste efficient procurement" and "Design for reuse and recycling".

- $57 \%$ of ADFs that did not implement DOW strategy stated that "lack of considering maintenance requirements" and "lack of contractor involvement during design process" represent the most barriers that hinder DOW implementation in ADFs. Other barriers included "lack of proper training", "poor supply chain collaboration"
- $\quad 72 \%$ of ADFs that implemented DOW stated that "Preparation and Briefing" and "Concept design" are the design phases that waste is expected to generate during the construction phase.

- All respondents mentioned that DOW principles are important to sustainability in PHPs. In addition, they stated that ADFs have to invest in educating and training architects on implementing DOW principles in order to reduce waste generated during the construction phase and enhance the sustainability of PHPs.

\section{Design Out Waste Framework for Achieving Sustainability in PHPs in Egypt}

Results of literature review, case studies and survey questionnaire led to developing a framework to assist ADFs implement DOW strategy during the design process in order to achieve sustainability in PHPs in Egypt.

\subsection{Definition and background}

Framework is described as a group of procedures, tools and techniques organised in a certain structure to develop a product, process or design [26]. The proposed framework DOW Implementation Framework (DOWIF) is a framework proposed by this research to facilitate implementing DOW strategy to achieve sustainability in PHPs in Egypt.

\subsection{The Need for the framework}

The DOWIF is required to provide some structured procedures for senior management in ADFs to implement DOW strategy to achieve sustainability in PHPs in Egypt. In addition, the framework is needed to overcome the barriers of implementing DOW strategy during the design of PHPs in ADFs. The necessity of this framework emerges from the importance to enhance building performance through enhancing the value delivered to clients, reducing project waste and energy consumption, protecting the environment, increasing end user satisfaction, enhancing the indoor climate and minimizing the project lifecycle maintenance cost. Accordingly, the framework will be applied for facilitating the implementation of DOW strategy towards achieving sustainability objectives. Moreover, the framework is required to fill the gap in construction literature towards DOW implementation in ADFs. 


\subsection{Development of the framework}

The development of the DOWIF was built on the outcome of literature review, case studies and data analysis gleaned from the survey questionnaire. Literature review indicated that the construction industry in general and PHPs in particular suffer from wastes generated during the construction phases. Many of these wastes are originated from the lack of proper decision and lack of implementing DOW during the design decision making process. In addition, there are a number of barriers that obstruct the implementation of DOW during the design process in ADFs. Moreover, results of the case studies showed that the projects that adopted DOW succeeded in achieving sustainability objectives and delivering values to their clients, where other projects that adopted traditional approaches failed to reduce project waste, energy consumption, indoor comfort and maintenance cost. Moreover, these findings are consistent with the outcome of the survey questionnaire. Respondents highlighted the limitations of the traditional design approach and the advantages of DOW strategy. Furthermore, they confirmed that DOW strategy was is not adopted in most of ADFs in Egypt and highlighted the barriers that affect its implementation in ADFs.

\subsection{Aim of the Framework}

The DOWIF is a novel business enhancement tool developed to facilitate the implementation of DOW to achieve sustainability objectives during the design process of PHPs in Egypt. This will enable improving the values provided to clients as well as improving the performance of projects throughout their life cycle.

\subsection{The Framework Description}

The framework consists of five functions, namely

- Identify implementation barriers;

- Establish implementation targets;

- Develop implementation plans;

- Execute implementation plans; and

- Monitor and evaluate implementation Plans (see Figure 8).

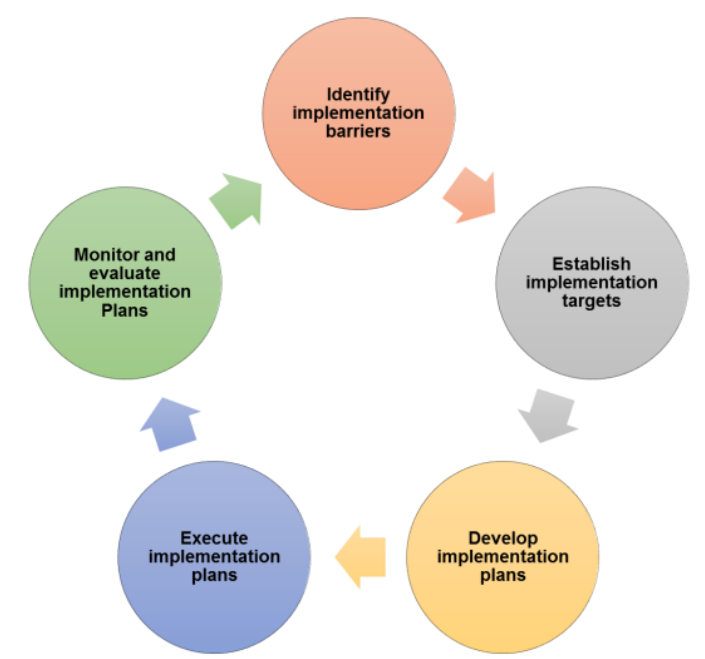

Figure (8) The Framework Functions (Developed by the Authors)

\subsubsection{Identify implementation barriers}

Identifying implementation barriers is an essential function of the framework. This is because it enables ADFs to define the barriers that hinder the implementation of DOW strategy into the design process of PHPs in Egypt. It is of prime significance to form a successful team (counting a skilled team leader) to conduct the study in hand. Accomplishing a harmony between the areas of expertise of team members who address different subject matters and have assorted knowledge and backgrounds is central for achieving the implementation targets. The study team should contain between six and twelve full time participants to maintain optimum productivity [27]. Convening an early orientation meeting is essential for discussing and agreeing on strategic matters such as duration of the study, required resources, responsibilities distribution. Support of the senior management will encourage the arrangement of required facilities and the application of the study decisions and proposals. The methods that could be used for data collection include literature review, field survey, meetings, interviews and case studies, while quantitative and qualitative techniques could be used for analysing the collected data. Team consensus and brainstorming and assessment criteria must be utilized for recognizing the root barriers and rank them as per their significance.

\subsubsection{Establish implementation targets}

Towards facilitating the implementation of DOW strategy in ADFs, the targets of implementing DOW into the design process in ADFs have to be established and approved by team members. This could be accomplished through utilizing brainstorming and group agreement techniques to produce and choose targets that address the identified 
barriers. Setting up implementation targets gives all participants the feel of ownership of these goals and encourages the team members to achieve them. Assessment criteria will be utilized to rank these targets as per their importance. Likewise, this function will result additionally in characterizing the rules to be utilized to gauge the achievement of carrying out DOW in the design process of PHPs in ADFs in Egypt.

\subsubsection{Develop implementation plans}

The "Develop implementation plans" function aims to establish the plans and actions needed to achieve the implementation targets. It includes a breakdown structure of the work to be performed and a matrix of team members' responsibilities. The first downsizes the work into manageable tasks and the later relates the task to be performed with the task owner. Moreover, the implementation plans must include expected risks and corrective actions to be adopted in case of the plans drifted from the agreed targets. In addition to that, the plans of communication between the team members have to be established to facilitate the reporting structure during the implementation of DOW into the design process of PHPs in ADFs in Egypt.

\subsubsection{Execute implementation plans}

The implementation plans developed previously have to be executed in this function. The execution plans may necessitate that employees engaged with the execution process be prepared and equipped with all necessary requirements and skills needed to ensure the fruitful execution of plans. However, the support of senior management is essential for offering the necessary facilities and will help accomplishing the execution targets. Executing the implementation plans should utilize the work approval framework, which approves the previous task before moving to the following task. This guarantees the quality of work performed. This function will help overcoming some of DOW barriers mentioned above such as considering maintenance requirements, contractor involvement during design process, training provision and supply chain collaboration.

\subsubsection{Monitor \& Evaluate implementation plans}

This function aims to ensure that the implementation of DOW during the design process of PHPs in ADFs in Egypt goes as planned. Remarks and input from the execution group will empower making restorative moves if plans were not carried out as arranged. Besides, this will help enhancing the effectiveness and efficiency of ADFs in future projects.

\subsection{Framework's Benefits and Limitations}

The framework will contribute towards improving the design process in ADFs and achieving sustainability objectives in PHPs. The framework will provide ADFs with a practical plan that explains how can ADFs implement DOW in the design process. The DOWIF provides a step by step framework to help ADFs overcome the deficiencies of the traditional process and overcoming the barriers that encounter DOW implementation. However, the DOWIF's achievement relies upon the encouragement of ADFs and the willingness of public authority to smooth the execution process. The utilization of the developed framework is tedious and time consuming process which requires full commitment from the team members. Because of the nature of the construction industry and busy schedule , this framework may not be welcomed and ADFs might be hesitant to adopt and implement this framework. The absence of governmental legislations and lack of awareness and support of senior management in ADFs obstruct the implementation of DOW in ADFs in Egypt. Due to the complexity of the construction process and its fast pace, the implementation of new framework might face some limitations. One of these limitations is the willingness to adopt a new strategy. To make an organization believe that adopting a new strategy that achieves sustainability is beneficial, the guidelines have to be highly efficient. Moreover, the lack of knowledge concerning the DOW strategy and sustainability must be encountered by spreading knowledge and awareness. The process to teach the required information needed to implement the framework might take time while the construction process is always accompanied by tight schedules.

\section{Conclusion and Recommendations}

The increasing population worldwide necessitated the development of PHPs to provide citizens with quality dwellings. However, this contributed towards generating significant amounts of waste which represent about $40 \%$ of the solid waste produced by the construction industry annually. The design decisions made during the deign process play a significant role towards generating waste during the construction phase, which ultimately affected the sustainability of the developed projects. This called for considering innovative strategies that reduce construction waste during the development process of PHPs. Accordingly, this research aimed to develop a framework to facilitate the implementation of DOW strategy to achieve sustainability in PHPs in Egypt. Within this research, literature review was used to investigate the nature of the construction industry in 
Egypt, waste in PHPs, DOW strategy and sustainability. In addition, analysis of two cases studies in UK and Egypt examined the benefits delivered due to the implementation of DOW strategy. Moreover, a survey questionnaire was conducted with representative sample of ADFs in Egypt to investigate their understanding and implementation of DOW strategy as an approach to minimize construction waste during the design process. This paper developed a matrix that correlates sustainability, DOW approaches and phases of the design process to analyse the case studies. In addition, it helped providing ADFs with insights about how DOW strategy could be used properly for achieving sustainability. Finally, the research developed a framework to enable the implementation of DOW strategy and assist ADFs achieving sustainability objectives in PHPs. At this point, the research come to the following recommendations:

- Raising the awareness of ADFs and project participants to adopt new approaches such as DOW strategy in order to improve the sustainability of PHPs and values delivered to clients.

- Encouraging collaboration and integration between project stakeholders during the design process to have a shared vision and maximize the achievement of sustainability objectives.

- Providing Senior Management of ADFs with successful PHPs that implemented DOW approaches will facilitate offering the needed resources and time for achieving successful results.

- Offering necessary training programmes, technologies, infrastructure and resources to enhance the technical skills of architects, design managers and other project participants to facilitate the implementation of DOW.

- Issuing laws, regulations and contracts that encourage the adoption of DOW in Governmental projects across the country and regulate the roles of different parties.

- Providing incentives for ADFs that implements DOW and committed to achieve sustainability objectives.

- Further research must be done regarding every single waste provided within the construction process through each type of building.

- More studies need to be conducted on the feasibility of DOW strategy in future housing projects in Egypt, specifically adaptive use and reuse materials.

- Educational institutions in Egypt, especially Architectural Engineering Departments, need to include in their curriculum adaptive reuse of materials in buildings to aid in achieving sustainable development. It would also help in achieving Egypt's 2030 vision, since it aligns with many of its goals.

- ADFs in Egypt need more specialization and training in the field of reusing materials efficiently since the number of ADFs that are specialized in waste management could not possibly handle the significant amount of waste produced from buildings in Egypt.

\section{References}

[1] Field, B. and Ofori, G., Construction and economic development - study. Third World Planning Review, 10 (1), 1988, pp.41-50.

[2] Essam, M. and Ehab, M., "Construction supply chain, inter-sectoral linkages and contribution to economic growth: the case study Egypt. The Egyptian center for economic study", Working Paper No. 184, [online], available from: www.eces.org.eg/MediaFiles/Uploaded_Fil es/5c2eab3f. pdf, 2015.

[3] Worldometer, Egypt Population, https://www.worldometers.info/worldpopulation/egypt-population/, 2021.

[4] Daoud, A. O., Othman, A., Robinson, H. and Bayyati, A., Exploring The Relationship Between Materials Procurement and waste Minimization In The Construction Industry: The Case OF Egypt. International Conference on Sustainability, Green Buildings, Environmental Engineering \& Renewable Energy (SGER 2018).

[5] Othman, A. A. E. and Youssef, L. Y. W., A Framework For Implementing Integrated Project Delivery In Architecture Design Firms In Egypt. Journal of Engineering, Design and Technology, DOI 10.1108/JEDT-02-20200047, 2020.

[6] Othman, A. A. E. and Abdelwahab, N. M. A., Achieving sustainability through integrating risk management into the architectural design process. Journal of Engineering, Design and Technology, Vol. (16), No. (1), 2018, pp. 2543.

[7] Osmani, M. An investigation of design waste causes in construction. In Waste Management and the Environment Iv, eds. M. Zamorano, C. 
A. Brebbia A. Kungolos, V. Popov \& H. Itoh, 491-498. Southampton: Wit Press, 2008.

[8] Shooshtarian, S., Maqsood, T., Wong, P., Khalfan, M., \& Yang, R., Construction Waste Management in Natural Disasters in Australia. 4-5.

https://doi.org/10.33552/GJES.2019.03.000 573, 2019.

[9] Daoud, A. O., Othman, A., Robinson, H. and Bayyati, A., Materials Procurement Strategies as an Approach to Reduce Materials Waste: A Comparison between the Egyptian Green Pyramid Rating System (GPRS) and the British Building Research Establishment Environmental Assessment Method (BREEAM), 2018.

[10] Daoud, A.O., Othman, A.A.E., Robinson, H., Bayyati, A., An Investigation Into Solid Waste Problem In The Egyptian Construction Industry: A Mini-Review. Waste Management and Research, Vol. 38(4), 2020, 371-382

[11] Egyptian Ministry of Environment (EMoE). (2017). Report on the environment status Egypt 2016.

[12] Arif, S. and Abaza, H., Towards Greening the Solid Waste Sector in the Middle East and North Africa Region, 2012.

[13] El-Sherbiny, R., Gaber, A. and Riad, M. Report of the Arab Forum for Environment and Development. Beirut, 2011. Available from: http://www.afedonline.org/Report2011/PDF/E n/chapter 7 Waste.pdf.

[14] Emas, R., The Concept of Sustainable Development: Definition and Defining Principles, Florida International University. 13. Retrieved from https://s3.amazonaws.com/academia.edu.d ocuments/43652555/5839GSDR_2015_SD _concept_definiton_rev.pdf?responsecontent-disposition=inline\%3B, 2015.

[15] US Environmental Protection Agency (EPA), Construction and Demolition Waste Landfills. Washington, D.C., 1995.

[16] Addis B and Talbot R., Sustainable Construction Procurement: A Guide to Delivering Environmentally Responsible Projects. Ciria, London, UK, Ciria C571, 2001.

[17] Abidin, N.Z.; Pasquire, C.L. Delivering sustainability through value management. Eng. Constr. Archit. Manag. 2005, 12, 168-180

[18] Othman, A.A.E., Ghaly, M. and Zainul Abidin, N., Lean Principles: An Innovative Approach for Achieving Sustainability in the Egyptian
Construction Industry. Organisation,

Technology and Management in Construction: An International Journal, Vol. 6, No. 1, 2014, pp. 917-932.

[19] BenzuJK., Three aspects of Sustainable Environmental Architecture. [Online]. Available from: http://www.architecturestudent.com/sustainable-design/threedimensions-of-sustainable-environmentalarchitecture/, 2009.

[20] Karlsson, R., A global Fordian compromise? - And what it would mean for the transition to sustainability. Environmental Science \& Policy 12(2), 2009, 190-197.

[21] Rodriguez, S., Roman, M., Sturhahn, S., and Terry, E., Sustainability

Assessment and Reporting for the University of Michigan's Ann Arbor Campus. Master's Thesis. University of Michigan: Ann Arbor: 1396, 2002.

[22] RIBA, RIBA Plan ofWork 2020, Royal Institute of British Architects, London, 2020.

[23] WRAP., Designing out Waste Tool for Buildings. A Full User Guide to WRAP's Designing out Waste Tool for Buildings, (February), 1-42, 2010, Retrieved from http://dowtb.wrap.org.uk/

[24] ADS, Architecture Design Scotland, Tigh-naCladach, online available from: https://www.ads.org.uk/wpcontent/uploads/Tigh-Na-Cladach.pdf, ,2010.

[25] Al Obour City Authority, Public Housing Projects Report, 2020.

[26] EDMS, Improving Building Performance through Integrating Constructability in the Design Process, Engineering Data

Management Services, 2010.

[27] Norton B. R. and McElligott, W. C., Value Management in Construction: A Practical Guide. London: Macmillan, 1995.

[28] Kocmanova, A., Hornungova, J., Docekalova, M. Sustainable Corporate Performance: Interaction between Environmental, Social, Corporate Governance and Economic Indicators, Int. J. of Applied Mathematics, Computational Science and Systems Engineering, pp. 113-121, Volume 2, 2020.

[29] Zhang, P., Liu, J. and Zhang, S. A Portable Environmental Parameter Monitor Based on STM32, International Journal of Circuits, Systems and Signal Processing, pp. 346-352, Volume 14, 2020.

\section{Creative Commons Attribution License 4.0} (Attribution 4.0 International, CC BY 4.0)

This article is published under the terms of the Creative Commons Attribution License 4.0

https://creativecommons.org/licenses/by/4.0/deed.en_US 